\title{
Los derechos humanos, sexuales y reproductivos de los estudiantes en los manuales de convivencia escolar
}

\author{
Human, sexual and reproductive rights of students \\ in the school coexistence manuals
}

\author{
Argemiro Toscano Luna \\ Magister en Educación de la Universidad Autónoma del Caribe Coordinador en la Institución Educativa Técnica \\ "Francisco de Paula Santander de Gálapa" (Atlántico). Página Web: http://inetfradpas.edu.co/inetfradpas/galapa/ \\ argemirotoscano@hotmail.com

\section{Rafael Peña Redondo} \\ Magister en Educación de la Universidad Autónoma del Caribe Licenciado en Educación Básica con Énfasis en \\ Ciencias Naturales y Educación. Docente de Aceleración del Aprendizaje de la Institución Educativa Técnica \\ Industrial San Antonio de Padua de Soledad.ietisanantoniodepadua@gmail.com rafaeljunior24@hotmail.com
}

\author{
Alfredo Castellar Guete \\ Magister en Educación de la Universidad Autónoma del Caribe alfredocastellarg@gmail.com \\ Docente Educación Básica en la Primaria Institución Educativa "León XIII” de San Jacinto. lualleal@yahoo.com
}

Para citar este artículo: Toscano A. , Peña R. Castellar A. (2017). Los derechos humanos, sexuales y reproductivos de los estudiantes en los manuales de convivencia escolar.

Escenarios. 15(1), pp. 47-70. Doi: http:/ / dx.doi.org/10.15665/esc.v15i1.1121

Recibido: enero 19 de 2017

Aceptado: febrero 20 de 2017

\section{RESUMEN}

Esta investigación sobre la necesidad de incluir y/o implementar acciones acerca de los Derechos Humanos, Sexuales y Reproductivos de los estudiantes en los manuales de convivencia escolar surgió ante la necesidad de hacer frente a una de las problemáticas que cada vez afecta más a la educación colombiana, relacionada con la convivencia escolar y su relación con el ejercicio de los derechos fundamentales de los estudiantes. Con este estudio se busca resolver el siguiente problema: ¿Qué Derechos Humanos, Sexuales y Reproductivos fundamentales reconocidos por la ley, son incluidos en los manuales de convivencia escolar? El objetivo propuesto es determinar la presencia de los derechos fundamentales Humanos, Sexuales y Reproductivos de los estudiantes reconocidos por la ley en los manuales de convivencia escolar de las instituciones educativas del Caribe colombiano. Es una investigación con enfoque cuantitativa, no experimental de tipo transversal descriptiva. Se seleccionó una muestra de seis reglamentos escolares de igual número de instituciones educativas del Caribe colombiano. Entre los hallazgos principales, se encontró que de los 38 derechos fundamentales de los estudiantes contenidos en la Constitución de 1991, la Ley 1098 de 2006 y la Ley 1620 de 2013, en los manuales de convivencia estudiados sólo son incluidos, en promedio, el 25.9\% de 
estos derechos, en tanto, el $74.1 \%$ restantes, son omitidos. Más específicamente, el estudio da cuenta de la exclusión del 71.9\% y el 85.4\%, respectivamente, de los Derechos Humanos y los Derechos Sexuales y Reproductivos, tomados como referente.

Palabras clave: Convivencia escolar, Derechos Humanos, Derechos Sexuales y Derechos Reproductivos.

\section{ABSTRACT}

This article is the result of research on human rights, sexual and reproductive of students on school coexistence manuals. This research was faced with the need to address one of the problems that increasingly affects more the Colombian education related school coexistence and the exercise of the fundamental rights of the students. This study seeks to solve the following problem: what human rights, sexual and reproductive fundamental recognized by law, are included in the school coexistence manuals? The proposed objective is to determine the presence of fundamental human rights, sexual and reproductive students recognized by the law in the educational institutions of the Colombian Caribbean school coexistence manuals. To comply with this objective is carried out a research quantitative not experimental of type transverse descriptive. We selected a sample of six equal number of educational institutions of the Colombian Caribbean school regulations. Among the main findings, found that of 38 students fundamental rights contained in the 1991 Constitution, the 1098 Act of 2006 and the 1620 law of 2013, in coexistence manuals studied only are included, on average, the $25.9 \%$ of these rights, meanwhile, the $74.1 \%$ remaining, are omitted. More specifically, the study gives an account of the exclusion of the $71.9 \%$ and the $85.4 \%$, respectively, of human rights and the sexual and reproductive rights, taken as a reference point.

Key words: School cohabitation, Human Rights, Sexual rights and Reproductive rights.

\section{INTRODUCCIÓN}

Una de las problemáticas que requiere pronta solución en la educación colombiana es la relacionada con la convivencia escolar y ejercicio de los Derechos Humanos, Sexuales y Reproductivos. Esto debido, a que cada vez más prolifera en la escuela la intolerancia, la discriminación, el conflicto interpersonal, el pandillismo, la drogadicción, el acoso, el vandalismo, así como la violencia física, verbal, virtual y relacional. Manifestaciones socio-culturales anómalas, que reflejan y guardan relación directa con el deterioro social y la crisis de valores por la que atraviesa la familia y la sociedad en general, así como con la situación conflictiva que vive el país.

De esta situación ha tomado conciencia el Estado colombiano, y por ello, junto al bajo rendi- miento, la convivencia escolar y el ejercicio de los derechos Humanos, Sexuales y Reproductivos se ha convertido en una de las grandes prioridades de las actuales políticas educativas del país. Una de las medidas más importantes tomadas por el Congreso de la República en tal sentido, fue la promulgación de la ley 1620 de 2013 y la consiguiente creación del "Sistema Nacional de Convivencia Escolar". Pues, con ella, se busca prevenir, promover y atender todo tipo de acción relacionada con la convivencia escolar, el respeto de los derechos fundamentales, para contribuir a la formación de buenos ciudadanos, capaces de valorar actos de reconciliación que promuevan la paz como medio de convivencia nacional.

El problema de la convivencia escolar y el ejercicio de los Derechos Humanos, Sexuales y Re- 
productivos, no sólo es una preocupación del Estado y la sociedad colombiana, sino también de otros países, Este tema empieza a cobrar fuerza entre los investigadores de la educación, particularmente, de Colombia, España y Chile. Esto es debido, en gran medida, al incremento de la violencia juvenil, en particular y de otras manifestaciones de violencia en general, que anteriormente eran propias de grupos que operaban en el campo y en las calles de las grandes ciudades. Esta situación cada vez más penetra al interior de la escuela y amenazan con desestabilizar los procesos educativos de estos países.

La revisión provisional de la literatura publicada sobre este asunto, da cuenta del creciente número de estudios que han abordado esta problemática en los últimos años, así como de la variedad de aspectos tratados. Entre las publicaciones realizadas en Colombia que abordan esta temática se encuentran las investigaciones de Areira, Cano y Jaramillo (2004); Bermejo, Sarmiento y Vizcaíno (2015); Bernal y Saker (2013); Boada et al. (2001); Caballero, Bonilla, Torres y Fonseca (2009); Cogollo y Peña (2014); Gil y Muñoz (2014); Ocampo, Briceño, Hernández y Olano (2010); Patiño (2011); Pava (2015); Quintero y Rentería (2009); Rodríguez (2011) y Sanabria (2013).

El análisis en conjunto de estas trece (13) investigaciones, demuestran que siete de ellas, hacen énfasis en las estrategias utilizadas en la escuela para mejorar la convivencia entre los estudiantes. Son estas las investigaciones de Areira, Cano y Jaramillo (2004); Bermejo, Sarmiento y Vizcaíno (2015); Bernal y Saker (2013); Boada et al. (2001); Patiño (2011); Ocampo, Briceño, Hernández y Olano (2010); y Quintero y Rentería (2009). Por su parte, los trabajos de Cogollo y Peña (2014); y de Gil y Muñoz (2014), se centran en el estudio del contexto sociocultural que incide en la convivencia escolar. Pava (2015), Rodríguez (2011) y Sanabria (2013), hacen énfasis en los Derechos Humanos, Sexuales y Reproductivos de los estudiantes, en tanto, el estudio de Caballero, Bonilla, Torres y Fonseca (2009), indagan sobre los procesos de participación de los estudiantes en la elaboración de los manuales de convivencia.
Entre los estudios desarrollados en España se pueden relacionar los trabajos de: Caballero (2010); Cangas, Gázquez, Pérez, Moldes y Rubio (2007); Conde (2013); Peralta (2004); y Rodríguez García et al. (2011). De estas investigaciones, las de Caballero (2010) y de Conde (2013), trabajan la relación existente entre la convivencia escolar y los procesos educativos. Y las de Cangas, Gázquez, Pérez, Moldes y Rubio (2007); Peralta (2004); y Rodríguez García et al. (2011), se centran en el estudio del contexto sociocultural que influye en la convivencia escolar.

Por su parte, entre los estudios desarrollados en Chile, es digno de mencionarse los trabajos de Casas (2008); Garretón (2013) y San Juan (2008). La primera de estas investigaciones, estudia los reglamentos que rigen la convivencia escolar en algunas instituciones educativas chilenas. La segunda, se centra en las percepciones que tienen los estudiantes, los docentes y los padres de familia respecto a la convivencia escolar. La tercera, estudia los significados que le dan los estudiantes y docentes a la convivencia escolar, así como la relación existente entre educación, los avances tecnológicos y la convivencia escolar.

Asimismo, el análisis de los diferentes estudios relacionados, pone de presente que, además de la diversidad de los aspectos tratados, las investigaciones son trabajadas desde diferentes perspectivas metodológicas. No obstante, a excepción de las investigaciones de Bernal y Saker (2013) y de Conde (2013), que trabajan la convivencia escolar desde la perspectiva del paradigma empírico- analítico y desde el enfoque tecnológico EFQM (European Foundation For Quallity Management), las demás investigaciones son desarrolladas con métodos y técnicas propias de las metodologías cualitativas, especialmente, con los procedimientos metodológicos etnográfico y hermenéutico-interpretativo. Entre las investigaciones desarrolladas con el método etnográfico, se observan los estudios de Bermejo, Sarmiento y Vizcaíno (2015); Caballero (2010); Caballero, Bonilla, Torres y Fonseca (2009); Cangas, Gázquez, Pérez, Moldes y Rubio (2007); Cogollo y Peña (2014); Gil y Muñoz (2014); Rodríguez García et al. (2011). Por su 
parte, las investigaciones de Areira, Cano y Jaramillo (2004); Boada et al. (2001); Casas (2008); Garretón (2013); Patiño (2011); Pava (2015); Quintero y Rentería (2009); Rodríguez (2011); Sanabria (2013) y San Juan (2008), son trabajadas a partir del paradigma hermenéutico-interpretativo. También, en el marco de las metodologías cualitativas, se encuentra el estudio de Peralta (2004), quien trabaja la convivencia escolar desde la perspectiva del modelo ecológico, y el estudio de Ocampo, Briceño, Hernández y Olano (2010), quienes proceden acorde con el método acción-participación.

Ahora bien, si se analizan los contenidos de las investigaciones antes relacionadas, se logra observar que la mayoría de éstas, se centran en el estudio del contexto sociocultural y en el diseño de estrategias educativas para mejorar las relaciones entre los distintos miembros de la comunidad educativa. Adicionalmente, se encuentran estudios que hacen énfasis en la percepción o el significado dado por la comunidad educativa a la convivencia escolar, así como en la participación de la misma en la elaboración de los reglamentos escolares. También, se encuentran investigaciones que hacen referencia a los Derechos Humanos, Sexuales y Reproductivos de los estudiantes.

No obstante, de los estudios que tocan el tema de los derechos fundamentales de los estudiantes, el de Pava (2015), se refiere exclusivamente a los derechos de la comunidad LGBTI, el de Rodríguez (2011), centra su objetivo en el derecho al libre desarrollo de la personalidad, en tanto que, el de Sanabria (2013), aborda el tema de los protocolos que sirven de garantía al ejercicio de los derechos de los estudiantes.

El objetivo es por una parte Caracterizar los derechos de los estudiantes incluidos en los manuales de convivencia de las instituciones educativas objeto de estudio, para observar si éstos son coherentes con los Derechos Humanos, Sexuales y Reproductivos exigidos por las leyes colombianas. Y complementariamente Cotejar los derechos de los estudiantes incluidos en los manuales de convivencia con respecto a los derechos fundamentales contenidos en la Consti- tución Política de Colombia de 1991 y demás normas que regulan los derechos en el país, con la intención de establecer cuáles Derechos Humanos, Sexuales y Reproductivos son omitidos y cuáles son tomados en consideración.

Sin duda es una investigación muy importante, si se toma en consideración que el Ministerio de Educación Nacional ha dado a las instituciones educativas un plazo perentorio de dos años, para reestructurar los manuales escolares de convivencia e introducir los derechos sexuales y demás derechos fundamentales omitidos en los mismos. Asimismo, es un estudio muy pertinente si se tiene en cuenta la gran polémica nacional desatada recientemente entre la Ministra de Educación, Gina Parody, y la diputada de Santander, Ángela Hernández, alrededor de la introducción de la ideología de género en la escuela. Polémica que tuvo su punto álgido en la realización de varias manifestaciones públicas de resonancia nacional, a favor de la familia y en contra de la directriz ministerial.

\section{Marco jurídico-conceptual a la investigación}

En 1948, en el marco de las políticas de reconciliación internacional, la Organización de las Naciones Unidas (ONU) dio a conocer la Declaración Universal de los Derechos Humanos. Once años después, la Asamblea General de las Naciones Unidas aprobó, la Declaración de los Derechos del Niño, mediante la cual se reconoció la preeminencia de estos derechos respecto a los derechos de los adultos. Posteriormente, el 1989, esta última Declaración fue ampliada en la Convención sobre los Derechos del Niño, reconociendo a los niños derechos económicos, sociales y culturales.

Los derechos fundamentales antes relacionados, fueron ratificados en la Constitución Política de Colombia de 1991 e incluidos en los Títulos I y II, referentes a los Principios Fundamentales y a los Derechos, Garantías y Deberes. Tres años después, con la promulgación de la Ley 115 de 1994 o Ley General de Educación, es introducida la asignatura de Educación ética y valores humanos como una de las áreas obligatorias y fundamentales que deben contribuir 
a la sana convivencia en la escuela. Además, se introducen los manuales de convivencia en los centros educativos, como dispositivo regulador de la convivencia en la escuela. Adicionalmente, con el decreto 1860 de 1994 (reglamentario de la Ley General de Educación), se normatiza todo lo relacionado con el gobierno escolar.

De manera complementaria en las últimas propuestas ministeriales, para el área de Ciencias Sociales (MEN, 2002; 2004), son introducidas las "Competencias ciudadanas" como uno de los grandes objetivos de la educación colombiana. Con el Plan Nacional Decenal de Educación 2006-2016 (MEN, 2007), se busca generar en los estudiantes el sentimiento patrio, el rescate de comportamientos cívicos, ciudadanos y de sana convivencia pacífica y la formación del estudiante en el respeto de los derechos fundamentales. Además, con la Ley 1098 de 2006 se pretende garantizar a los niños, a las niñas y a los adolescentes su pleno y armonioso desarrollo.

No obstante, en los últimos años ha tomado fuerza el problema de la violencia escolar y de la transgresión de los derechos Humanos, sexuales y reproductivos en la escuela. Y por ello, junto al bajo rendimiento escolar, la convivencia escolar se ha convertido en una de las grandes prioridades de las actuales políticas educativas del país. Una de las medidas más importantes tomadas por el Congreso de la República en tal sentido, fue la promulgación de la ley 1620 de 2013 y el decreto 1965 del mismo año, con los cuales se busca formar ciudadanos constructores de ambientes de paz y de una sociedad democrática, participativa, pluralista e intercultural.

Como medida complementaria a la ley 1620 de 2003, el Instituto Colombiano para el Fomento de la Educación Superior (ICFES) y el Ministerio de Educación Nacional (MEN, 2013), siguiendo las directrices nacionales, 2002 y 2004, convirtieron las Competencias Ciudadanas en una de las finalidades básicas de las Ciencias Sociales y de la educación colombiana. En consecuencia, en las nuevas orientaciones para alinear las pruebas Saber $3^{\circ}, 5^{\circ}, 9^{\circ} 11^{\circ}$ y Saber Pro, el ICFES y MEN (2013), unieron las pruebas de
Competencias Ciudadanas y de Ciencias Sociales en una, y le dieron el carácter de competencia genérica. Es decir, en un saber para toda la vida que resulta indispensable para el desempeño social y laboral.

Tres conceptos básicos se manejan a lo largo del estudio: Convivencia Escolar, Derechos Humanos y Derechos Sexuales y Reproductivos. Sobre el primer concepto, existen muchas y variadas connotaciones. Sin embargo, cinco definiciones llaman la atención por concebir la convivencia escolar desde ópticas diferentes. Se trata de las definiciones de Delors (1996), de Ortega (2007), de Carretero (2008), del Ministerio de Educación Nacional de Colombia (2013) y del Ministerio de Educación de la República de Chile (2015).

Por su parte, Ortega (2007), entiende la convivencia escolar como una situación de la vida escolar, donde además de ausencia de violencia, deben existir relaciones interpersonales y grupales satisfactorias entre los distintos miembros de la comunidad escolar. Carretero (2008), la define como el proceso mediante el cual los distintos miembros de la comunidad educativa aprenden a convivir con los demás. El Ministerio de Educación Nacional (2013), entiende la convivencia como: "la acción de vivir en compañía de otras personas en el contexto escolar y de manera pacífica y armónica." (p. 25). Por su parte, el Ministerio de Educación de Chile (2015), la concibe: "como un fenómeno social cotidiano, dinámico y complejo, que se expresa y construye, desde la interacción que se vive entre distintos actores de la comunidad educativa" (p. 25).

Como se podrá observar, las anteriores definiciones concuerdan, en concebir la convivencia escolar como las relaciones armónicas y pacíficas que deben existir entre los miembros de la comunidad educativa. Pero también, se pueden advertir diferencias en la manera de pensar esta interrelación. Delors (1996), la entiende como parte del proceso educativo. Ortega (2007), la concibe como una situación de interrelación deseable. Carretero (2008), la piensa como un proceso de aprendizaje. Para El Ministerio de 
Educación Nacional de Colombia (2013), es un estado positivo de interacción humana. Y, el Ministerio de Educación de Chile (2015), la concibe como un fenómeno social que se construye en el proceso de interacción humana.

No obstante, ninguna de estas definiciones trascienden el terreno de la interrelación humana, excluyendo la interrelación existente entre la comunidad educativa con el medio natural y cultural. Por ello, apoyándonos en la visión de Arrieta (2016), entender la convivencia escolar como el sistema complejo de interrelaciones que establecen los distintos miembros de la comunidad educativa entre sí, lo mismo que con el entorno natural y cultural de la escuela. En consecuencia, los reglamentos escolares, además de contener normas referentes a la convivencia entre los distintos miembros de la comunidad educativa, deben contener, y contienen, reglas para regular la convivencia humana con el medio natural y cultural en que se desenvuelven. Acogiendo el criterio básico de las Naciones Unidas en su Declaración Universal de los Derechos Humanos (ONU, 1949, Art. $2^{\circ}$ ), se entenderá que todos aquellos derechos universales, inalienables e inherentes son para todos los seres humanos, sin distinción alguna de nacionalidad, lugar de residencia, sexo, origen nacional o étnico, color, religión, lengua, o cualquier otra condición. Asimismo, dado que la noción suministrada por la Comisión Nacional de los Derechos Humanos de México (2010-2016, p. $1)$, cumple con las expectativas de la presente investigación, los Derechos Humanos son definidos como: "el conjunto de prerrogativas sustentadas en la dignidad humana, cuya realización efectiva resulta indispensable para el desarrollo integral de la persona."

Por otra parte, tomando en consideración los criterios conceptuales expresados en el artículo $2^{\circ}$ de la Ley 1620 de 2013 y en la Sentencia T-565 de 2013 de la Corte Constitucional de Colombia, se entenderá por Derechos Sexuales y Reproductivos, a aquellos Derechos Humanos que buscan proteger el desarrollo pleno de la sexualidad, el reconocimiento de la identidad u orientación sexual y de género, así como tomar decisiones autónomas para ejercer una se- xualidad libre y responsable. Acorde con esta definición, la Ley 1620 de 2013 sugiere formar personas capaces de reconocerse como sujetos activos titulares de derechos Humanos Sexuales y Reproductivos y capaces de respetarse a sí mismo y de relacionarse con los demás de manera responsable.

\section{Metodología}

De manera particular, se toma como referente metodológico el paradigma cuantitativo, no experimental transversal, diseño descriptivo (Hernández, Fernández y Baptista, 2014). Acorde con este tipo de investigación, desde el punto de vista procedimental, se sigue un proceso lógico deductivo-secuencial. Es decir, el análisis descriptivo, se inicia con un inventario de los Derechos Humanos, Sexuales y Reproductivos contenidos en las normas tomadas como referente (la Constitución Política de Colombia de 1991, la Ley 1098 de 2006 y la Ley 1620 de 2013). Luego, se hace la relación de los derechos de los estudiantes incluidos en los diferentes manuales escolares de convivencia estudiados para cotejarlos con los derechos fundamentales contenidos en las normas utilizadas como referentes. Esto, con el fin de establecer cuáles derechos humanos, sexuales y reproductivos están incluidos en cada uno de los reglamentos escolares, y cuáles son omitidos. Finalmente, se hace un análisis comparativo y de conjunto de los derechos incluidos y omitidos en los diferentes reglamentos escolares

De conformidad con lo anterior, el estudio sólo se limita a recoger información sobre los derechos fundamentales de los estudiantes incluidos y omitidos en los manuales de convivencia, sin indicar cómo se relacionan o se condicionan estos, y sin clara intención predictiva. Esto, según Hernández, Fernández y Baptista (2014), le proporciona a la investigación el carácter de estudio descriptivo con diseño transversal no experimental, que no pretende probar hipótesis, sino sólo evaluar los manuales de convivencia escolar, en materia de derechos fundamentales. Se recurrió a un tipo de muestra dirigida o no probabilística. Esto es, se escogieron seis manuales de convivencia, de seis institucio- 
nes educativas de la costa Caribe colombiana, muestra no probabilística, Hernández, Fernández y Baptista (2014), seleccionada por el criterio que los manuales de convivencia escogidos correspondieran a instituciones educativas de la costa Caribe Colombiana, pertenecientes al sector oficial y con una población de estudiantes correspondiente a estrato sociocultural semejante. Además, se debía contar con el aval de las autoridades y órganos directivos de dichas instituciones y por practicidad que fueran afines, accesibles y compatibles con los lugares de labor diaria de los investigadores.

la muestra quedo constituida por los corpus normativos pertinentes de las instituciones educativas "Francisco de Paula Santander" de Galapa, "Nuestra Señora de la Candelaria" de Malambo, "Blas Torres de la Torre" de Soledad, "San José" de Barranquilla, "Antonia Santos" de Molinero y "León XIII" de San Jacinto. Las cinco primeras, correspondientes al Departamento del Atlántico, y la última, al Departamento de Bolívar.

Se utilizaron los elementos conceptuales y procedimentales propios de las técnicas de revisión documental y de análisis de contenido. Acorde con estas últimas, la muestra fue codificada y categorizada con el propósito de escoger las unidades y las categorías o variables que debían servir de ejes al análisis descriptivo.

Para la codificación de la muestra se tuvo en cuenta la propuesta de Krippendorff (1990), quien sugiere tres tipos de unidades en el examen de cada texto: muestreo, registro y contexto. Unidades, que para este caso particular, corresponden, en orden respectivo, a los seis manuales de convivencia seleccionados, a los derechos de los estudiantes de cada uno de los reglamentos estudiados, y a la Constitución y demás normas tomadas como referente. Las categorías o variables que se utilizan como ejes en el estudio, se realizó un examen preliminar de los derechos fundamentales exigidos por la ley 1620 de 2013, que sirve de referente básico en el plano educativo. Como resultado de este examen inicial, se encontró que esta ley reclama la inclusión de dos tipos de derechos fun- damentales en los manuales de convivencia: los Derechos Humanos y los Derechos Sexuales y Reproductivos, los que sirvieron asimismo, de base para seleccionar las categorías.

Dos categorías principales sirven entonces de eje a la presente investigación: Derechos Humanos y Derechos Sexuales y Reproductivos. En la categoría Derechos Humanos, se toman como referentes los derechos fundamentales reconocidos por la Constitución Política de Colombia de 1991, la Ley 1098 de 2006, la ley 1620 de 2013, así como las sentencias de la Corte Constitucional en esta materia. En la categoría Derechos Sexuales y Reproductivos, como su nombre lo indica, se hace relación, de manera particular, a todos aquellos derechos que guardan relación directa con la sexualidad y la reproducción, contenidos igualmente en las normas tomadas como referentes.

Una vez seleccionadas las categorías, se procedió a estructurar el instrumento (los cuadros de registro), que sirve de guía al análisis. Para este efecto, además de lo explícito o lo expreso en los textos estudiados, también se tuvo en cuanta las omisiones en los mismos. Es decir, que además de los Derechos Humanos, Sexuales y Reproductivos incluidos en los distintos manuales de convivencia, se tomó en consideración aquellos derechos fundamentales omitidos en los mismos.

Superada la fase anterior, se procedió a realizar el análisis descriptivo siguiendo una secuencia general deductiva. Es decir, se comenzó con el inventario y clasificación de los derechos fundamentales contenidos en las normas tomadas como referentes (unidades de contexto). Se continuó con la relación y clasificación de los derechos de los estudiantes contenidos en los seis manuales de convivencia estudiados (unidades de registro). Se terminó con el análisis comparativo que resultó del cotejo de los derechos fundamentales de los estudiantes contenidos en los manuales y los exigidos por la ley. Esto, con el fin de establecer cuáles Derechos Humanos, Sexuales y Reproductivos están incluidos en los reglamentos escolares, cuáles son omitidos, para sugerir al final una relación de los 
derechos que deben ser incluidos al reformar o actualizar este tipo de corpus normativo.

\section{Fases del análisis \\ Resultados del análisis y discusión}

De conformidad con el procedimiento metodológico propuesto, el proceso analítico se inició con la búsqueda de un modelo del Ministerio de Educación Nacional (MEN), donde estuvieran consignados los Derechos Humanos, Sexuales y Reproductivos fundamentales que requieren observarse al momento de elaborar los manuales de convivencia escolar. Esto, con el propósito de tener una relación de derechos base que pudieran servir de referente al momento de cotejar los derechos de los estudiantes incluidos en los distintos manuales escolares de convivencia examinados.

Para ello fueron revisadas la Ley 115 de 1994 o Ley General de la Educación, el Decreto 1860 de 1994, la Ley 1620 de 2013 y demás normas ministeriales que sirven de fundamento a la elaboración de los manuales de convivencia escolar. Pero, dado que no se encontró ningún "modelo oficial" donde estuvieran relacionados los Derechos Humanos, Sexuales y Reproductivos fundamentales a tener en cuenta en la escuela, hubo necesidad de construir uno, tomando como base los derechos que según la Corte Constitucional (Sentencia T-1233 de 2003), deben observarse a la hora de elaborar los manuales de convivencia.

La Corte hace referencia a todos aquellos derechos y principios que se sustentan en el artículo $1^{\circ}$ de la Constitución, que apuntan hacia el respeto a la dignidad humana y la diversidad étnica, cultural y social de la población colombiana. Entre los derechos superiores constitucionales, la Corte Constitucional de Colombia sugiere tener en cuenta los derechos contenidos en los artículos 13, 16, 18, 20, 29 y 67, referentes a la igualdad ante la ley, al libre desarrollo de la personalidad, a la libertad de conciencia, a la libertad de expresión, al debido proceso y a la educación, respectivamente.

El inventario de los Derechos Humanos, Sexuales y Reproductivos superiores sugeridos por la Corte Constitucional, unido a otros Derechos Humanos, Sexuales y Reproductivos contenidos en la Constitución de 1991, la Ley 1098 de 2006 y la Ley 1620 de2013, arrojó como resultado el siguiente cuadro:

Cuadro 1. Derechos Humanos, Sexuales y Reproductivos fundamentales contenidos en la Constitución Política Nacional de Colombia y la Ley 1098 de 2006

\begin{tabular}{|l|l|}
\hline \multicolumn{1}{|c|}{ Constitución Política de Colombia (1991) } & \multicolumn{1}{|c|}{ Ley $\mathbf{1 0 9 8}$ de $\mathbf{2 0 0 6}$ o Ley de la Infancia y la Adolescencia } \\
\hline Derecho a la vida (art. 11) & \multicolumn{1}{c|}{ Derechanos fundamentales } \\
\hline Derecho a un trato justo y humano (art. 12) & Derecho a la protección integral (art. 7) \\
\hline Derecho a la lgualdad ante la ley (art. 13) & Derecho a la integridad personal (art. 18) \\
\hline Libertad de conciencia (art. 18) & Derechos a la rehabilitación y resocialización (art. 19) \\
\hline Libertad de cultos (art. 19) & Derechos de protección (art. 20) \\
\hline Libertad de expresión (art. 20) & Derecho a la libertad y seguridad personal (art. 21) \\
\hline Derecho a la honra (art. 21) & Derecho al desarrollo integral (art. 29) \\
\hline Derecho a vivir en paz (art. 22) & Derecho a la información (art. 34) \\
\hline Derecho de petición (art. 23) & Derecho de los niños con discapacidad (art.36) \\
\hline Derecho al debido proceso (art. 29) & Obligaciones especiales de los centros educativos (art. 42) \\
\hline Libertad de reunión y manifestación pública (Art. 37) & Obligación ética de las instituciones educativas (art. 43) \\
\hline Derecho de libre asociación (art. 38) & Obligaciones complementarias de las instituciones (art. 44) \\
\hline Derecho a elegir y ser elegido (art. 40) & \multicolumn{1}{|c|}{ Derechos sexuales y reproductivos } \\
\hline Derechos a una educación ciudadana (art. 41) & Corresponsabilidad (art.10) \\
\hline
\end{tabular}


Escenarios • Vol. 15, No. 1, Enero - Junio de 2017, págs. 47-70

\begin{tabular}{|l|l|}
\hline Derecho a la formación integral (art. 45) & La responsabilidad parental (art. 14) \\
\hline Derecho al saneamiento ambiental (art. 49) & Derecho a tener y a no separarse de la familia (art.22) \\
\hline Derecho al deporte, la recreación y la cultura (art. 52) & Derecho a la identidad (art. 25) \\
\hline Derecho a la educación (art. 67) & Derecho a la intimidad (art. 33) \\
\hline Derecho a la salud (art. 79) & \\
\hline \multicolumn{1}{|c|}{ Derechos sexuales y reproductivos } & \\
\hline Derecho al buen nombre (art. 15) & \\
\hline Derecho al Libre desarrollo de su personalidad (art. 16) & \\
\hline
\end{tabular}

Fuente: Constitución Política de Colombia (1991); Ley 1098 de 2006.

Como se podrá observar en el cuadro anterior, fueron seleccionados 38 derechos fundamentales, que se considera deben ser tenidos en cuenta a la hora de construir o reconstruir cualquier manual de convivencia escolar. De estos 38 derechos fundamentales, atendiendo a las definiciones dadas en el apartado relativo a los fundamentos conceptuales, 30 de ellos (78.9\%), son clasificados en el ámbito de los Derechos Humanos, en tanto los 8 ocho restantes $(21.1 \%)$, son catalogados en el campo de los Derechos Sexuales y Reproductivos.

Continuando con el proceso de análisis, se procede a hacer el inventario de los derechos de los estudiantes contenidos en cada uno de los

seis reglamentos escolares de las instituciones educativas seleccionadas, y se cotejan de inmediato con el inventario de derechos fundamentales tomados como referente en el Cuadro 1. Esto, con el fin de observar cuáles derechos de los reglamentos escolares se corresponden con los Derechos Humanos y Derechos Sexuales y Reproductivos tomados como referente y cuáles son omitidos.

Con respecto al Manual de Convivencia de la Institución Educativa Técnica Francisco de Paula Santander de Galapa (Atlántico), la revisión de los derechos de los estudiantes contenidos en este reglamento arroja el siguiente resultado:

Cuadro 2. Derechos de los estudiantes. Institución Educativa Técnica Francisco de Paula Santander de Galapa

\begin{tabular}{|ll|}
\hline \multicolumn{1}{|c|}{ Derechos Humanos contenidos en la Constitución de 1991} \\
\hline 1. & No ser discriminado ni excluido de ninguna actividad curricular o extracurricular (art. 13) \\
\hline 2. & Expresar con libertad y responsabilidad sus opiniones (art. 20) \\
\hline 3. & Promover iniciativas y peticiones respetuosas y obtener pronta respuesta (art. 23) \\
\hline 4. & Debido proceso (art. 29) \\
\hline 5. & Formación integral ética, moral, cultural, recreativa y deportiva (art. 45) \\
\hline 6. & Disfrutar del ambiente sano y recibir orientaciones oportunas (art. 49) \\
\hline 7. & Disfrutar del descanso y del tiempo libre, el esparcimiento, la lúdica, el deporte, la cultura y las artes (art. 52) \\
\hline 8. & Continuidad en la educación (art. 67) \\
\hline & Derechos Humanos contenidos en la Ley 1098 de 2006 \\
\hline 9. & Participar en la planeación, realización y evaluación de los procesos de enseñanza y aprendizaje (art. 42) \\
\hline 10. Recibir atención amable, sincera y cordial (art. 42) \\
\hline Derechos Sexuales y Reproductivos contenidos en la Constitución \\
\hline 11. Libre desarrollo de su personalidad (art. 16) \\
\hline Derechos Sexuales y Reproductivos contenidos en la Ley 1098 de 2006 \\
\hline 12. Tener un acudiente que lo represente \\
\hline Derechos Institucionales \\
\hline 13. Conocer los resultados a tiempo de las evaluaciones \\
\hline
\end{tabular}

Fuente: Manual de Convivencia de la Institución Educativa Técnica Francisco de Paula Santander de Galapa, Art. 36. 
Ahora bien, si se coteja los derechos de los estudiantes incluidos en el Cuadro 2 con los derechos fundamentales contenidos en el Cuadro 1 , tomado como referente, se puede establecer que los derechos señalados con los numerales 1 al 8 del cuadro 2, corresponden en forma respectiva, a los artículos $13,20,23,29,45,49$, 52, 67 de la Constitución. Artículos de la Carta Magna que contienen los derechos fundamentales a la igualdad ante la ley, a la libertad de expresión, a realizar peticiones respetuosas, al debido proceso, a una formación integral, a un ambiente sano, al descanso y la recreación y a la educación, respectivamente.

Igualmente, se puede constatar que los derechos de los estudiantes señalados con los numerales 9 y 10 del cuadro 2, coincide en forma respectiva con los derechos básicos relacionados con el buen trato y la participación en la planeación, ejecución y evaluación del proceso educativo, reconocidos en los artículos 42 y 43 de la ley 1098 de 2006. Los numerales 11 y12 del mismo cuadro, referentes al libre desarrollo de la personalidad y la responsabilidad parental, se encuentran corroborados en el artículo 16 de la Constitución y el artículo 14 de la Ley 1620 de 2013 , respectivamente. Por su parte, el numeral 13 incluido en el cuadro 2 y relacionado con el conocimiento de las evaluaciones, corresponde a un derecho que sólo tiene competencia en el plano institucional.

El cotejo entre los dos cuadros, igualmente pone de presente la omisión en este manual escolar de convivencia de Derechos Humanos fundamentales como los derechos a la vida, a un trato justo y humano, a la libertad de conciencia, a la libertad de culto, a la honra, a vivir en paz, a la libertad de reunión y manifestación, a la libertad de asociación, a la libertad de elegir y ser elegido y a una educación ciudadana. Todos ellos, contenidos en los artículos 11, 12,
$18,19,21,22,37,38,40,41,45,79$ de la Constitución Política de Colombia de 1991. Asimismo, la comparación da cuenta de la exclusión del derecho sexual y reproductivo contenido en el artículo 15 de la Carta Magna, referente a la intimidad personal y el buen nombre.

Por otra parte, se pasan por alto Derechos Humanos fundamentales de los niños y jóvenes, como los derechos a la protección integral, a la integridad personal, a la rehabilitación y resocialización, a la protección, a la seguridad personal, al desarrollo integral, a la información, de los niños con discapacidades. Derechos que están reconocidos en los artículos 7, 18, 19, 20, 21, 29, 34 y 36 de la Ley 1098 de 2006. De igual manera son omitidos los Derechos Sexuales y Reproductivos referentes a la corresponsabilidad en la educación, la perspectiva de género, la identidad y la intimidad personal, reconocidos en los artículos $10,12,22,25$ y 33 de la misma ley.

Vistas las cosas de otro modo, se puede apreciar que de los 38 derechos fundamentales tomados en el Cuadro 1 como referencia, 26 de ellos, es decir, el 73.7\% de los Derechos Humanos, Sexuales y Reproductivos relacionados, fueron omitidos. Sólo 12 de estos derechos fundamentales, o sea, el $26.3 \%$, fueron incluidos al elaborar el manual de convivencia escolar en la Institución Educativa Técnica Francisco de Paula Santander de Gálapa. De estos 12 derechos fundamentales, 10 corresponden a los Derechos Humanos, y dos, a los Derechos Sexuales y Reproductivos, lo que representa, en forma respectiva, el $33.3 \%$ y el $25 \%$, de los 30 Derechos Humanos y de los ocho Derechos Sexuales y Reproductivos, inventariados en el Cuadro 1. En cuanto al Manual de Convivencia a la Institución Educativa Nuestra Señora de la Candelaria de Malambo, en su artículo 20, están relacionados los derechos que aparecen en el Cuadro 3: 
Cuadro 3. Derechos de los estudiantes. Institución Educativa Nuestra Señora de la Candelaria de Malambo

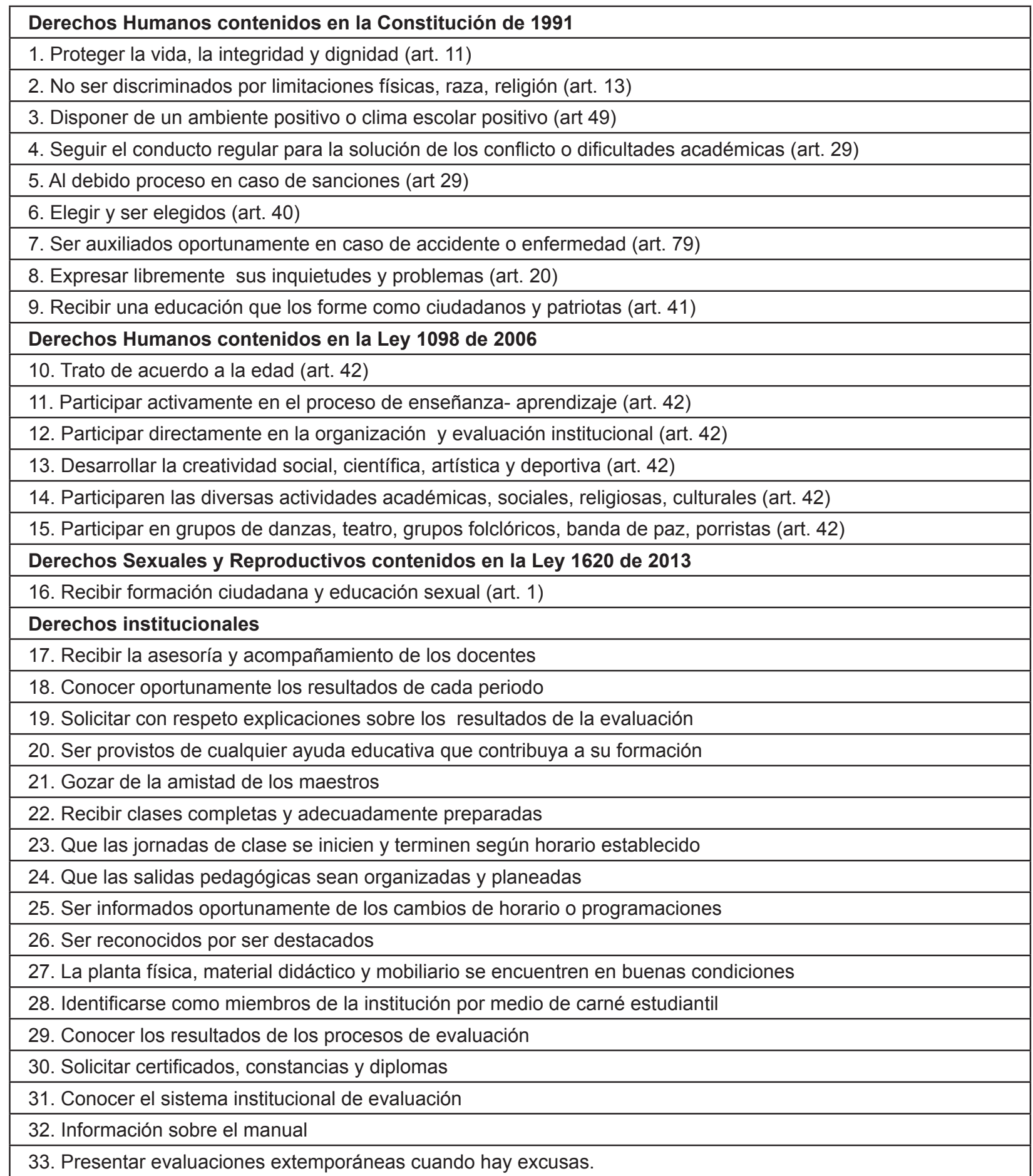

Fuente: Manual de Convivencia de la Institución Educativa Nuestra Señora de la Candelaria, Art. 20. 
La operación de cotejo entre los cuadros 3 y 1 , pone de presente que los derechos señalados con los numerales 1 al 9 del Cuadro 3, corresponden a los derechos fundamentales a la vida, a la igualdad, a un ambiente sano, al debido proceso, a elegir y ser elegido, a la salud, a la libertad de expresión y a la educación ciudadana. Derechos Humanos que se encuentran ratificados por los artículos 11, 13, 49, 29, 40, 79, 20 y 41 de la Constitución de 1991. Los derechos relacionados con los numerales 10 al 15 en el Cuadro 3, referente al trato de acuerdo a la edad, la participación en el proceso educativo y la participación en los grupos artísticos y culturales, se encuentran circunscritos en el Artículo 42 de la Ley 1098 de 2006.

Por otra parte, los derechos que aparecen en el Cuadro 3 con los numerales 17 al 33, sólo tienen competencia en el ámbito de la Institución Educativa Nuestra Señora de la Candelaria de Malambo. Asimismo, se ha de advertir que de todos los derechos relacionados en el Cuadro 3, salvo el numeral 16 que encaja con artículo $1^{\circ}$ de la ley 1620 de 2013, no se incluye ninguno de los Derechos Humanos, Sexuales y Reproductivos contenidos en la Constitución Política de Colombia de 1991 y en la Ley 1098 de 2006.

Ahora bien, si se realiza la misma operación de cotejo respecto a los derechos omitidos en el manual de convivencia de la Institución Educativa Nuestra Señora de la Candelaria de Malambo, se puede constatar que en el cuadro 3 se pasan por alto muchos Derechos Humanos fundamentales. Se hace referencia a los artícu$\operatorname{los} 12,13,18,19,21,23,37,38,45,49,52$ y 67 de la Constitución Política Nacional de Colombia, que salvaguardan los derechos a un trato justo y humano, a la igualdad ante la ley, a las liber- tades de conciencia y culto, a la honra, de petición, a las libertades de reunión y asociación, a la formación integral, a un ambiente sano, a la recreación y a la educación.

De igual manera, son omitidos Derechos Humanos básicos como los incluidos en los artículos $7,18,19,20,21,29$ y 36 de la ley 1098 de 2006. Se hace referencia a los derechos fundamentales a la protección integral, a la integridad personal, a la rehabilitación y resocialización, a la protección, a la libertad y seguridad personal, al desarrollo integral, y de los niños con discapacidad. Asimismo, son excluidos los Derechos Sexuales y Reproductivos referentes a la corresponsabilidad en la educación, la perspectiva de género, a tener y no separarse de la familia, a la identidad y a la intimidad, correspondientes a los artícu$\operatorname{los} 10,12,14,22,25$ y 33, de la misma ley.

Ahora bien, si se convierten los datos anteriores a cifras numéricas, se puede constatar que de los 38 derechos fundamentales contemplados en el Cuadro 1 como referentes, 22 de ellos (57.9\%), son omitidos por completo, en tanto los 16 restantes $(42.1 \%)$, aparecen incluidos en el manual de convivencia de la Institución Educativa Nuestra Señora de la Candelaria de Malambo. De estos 16 derechos fundamentales, 15 corresponden a los Derechos Humanos, y sólo 1, a los Derechos Sexuales y Reproductivos. Esto, representa, en forma respectiva, el $50 \%$ y el $12.5 \%$, de los 30 Derechos Humanos y de los ocho Derechos Sexuales y Reproductivos contenidos en el Cuadro 1.

En lo que respecta a la Institución Educativa Técnico Industrial Blas Torres de la Torre (ITIDA) de Soledad, en su reglamento interno son incluidos los derechos de los estudiantes relacionados en el Cuadro 4. 
Cuadro 4. Derechos de los estudiantes. Institución Educativa Técnico Industrial Blas Torres de la Torre de Soledad (Atlántico)

\begin{tabular}{|l|}
\hline Derechos Humanos contenidos en la Constitución de 1991 \\
\hline 1. Libertad de conciencia (art. 18) \\
\hline 2. Libertad de cultos (art. 19) \\
\hline 3. A expresar sus opiniones con respeto (art. 20) \\
\hline 4. A la honra y al buen nombre (art. 21) \\
\hline 5. A presentar solicitudes respetuosas (art. 23) \\
\hline 6. A elegir y ser elegido (art. 40) \\
\hline 7. A la formación integral (art. 45) \\
\hline 8. Al descanso, a la recreación, el deporte, la cultura y las artes (art. 52) \\
\hline Derechos Humanos contenidos en la Ley 1098 de 2006 \\
\hline 9. A su integridad personal (art. 18) \\
\hline 10. A ser escuchado, orientado y asistido (art. 42) \\
\hline 11. Ser tratado con respeto, comprensión y justicia (art. 42) \\
\hline Derechos Sexuales y Reproductivos contenidos en la Constitución de 1991 \\
\hline 12. Al libre desarrollo de la personalidad (art. 16) \\
\hline Derechos Sexuales y Reproductivos contenidos en la Ley 1098 de 2006 \\
\hline 13. A una identidad personal y familiar (art. 25) \\
\hline
\end{tabular}

Fuente: Manual de Convivencia de la Institución Educativa Técnico Industrial Blas Torres de la Torre (ITIDA).

A partir del cotejo de los derechos incluidos en los cuadros 4 y 1 , respectivamente, se puede colegir que los derechos relacionados con los numerales 1 al 8 en el Cuadro 4 , son reconocidos en los artículos, 18, 19, 20, 21, 23, 40, 45 y 52 de la Constitución Política Nacional. Artículos de la Carta Magna que corresponden, en forma respectiva, a la libertad de conciencia, a la libertad de cultos, a la libre expresión, a la honra, a presentar peticiones respetuosas, a elegir y ser elegido, a la formación integral y a la recreación y el deporte.

Por otra parte, los derechos relacionados con los numerales 9, 10 y 11 del Cuadro 4, son confirmados por los artículos 18 y 42 de la Ley 1098 de 2006, referentes a la integridad personal, a ser orientado y a ser tratado con respeto, justicia y comprensión. Asimismo, en el Cuadro 4 son relacionados con los numerales 12 y 13, los derechos al libre desarrollo de la personalidad y a una identidad personal y familiar, reconocidos en los artículos 16 y 25 de la Constitución y la Ley 1098 de 2006, los cuales corresponden al ámbito de los Derechos Sexuales y Reproductivos.
La operación de cotejo entre los cuadros 1 y 4 , también nos pone de presente que en el Manual de Convivencia de la Institución Educativa Técnico Industrial Blas Torres de la Torre (ITIDA) de Soledad, son omitidos algunos derechos fundamentales. Se hace referencia a los Derechos Humanos fundamentales a la vida, el buen trato, a la igualdad ante la ley, a vivir en paz, al debido proceso, a la libertad de reunión y manifestación, a la libre asociación, a una educación ciudadana, a la educación y a la salud, incluidos en los artículos: 11, 12, 13, 22, 29, 37, 38, 41, 49, 67, 79 de la Constitución Política de Colombia.

De igual manera, en este manual de convivencia no se toma en consideración los Derechos Humanos contenidos en los artículos 7, 18, 19, 20, 21, 29, 34, 36, 42, 43 y 44 de la Ley 1098 de 2006. Artículos que en esta norma hacen referencia a los derechos a la protección integral, la integridad personal, a la rehabilitación y resocialización, a la protección, a la seguridad personal, al desarrollo integral, a la información, de los niños discapacitados, a la educación ética y demás derechos educativos. 
También, son excluidos Derechos Sexuales y Reproductivos fundamentales tales como el derecho a la intimidad personal y al buen nombre, reconocido por la Constitución de 1991 en su artículo 15. Asimismo, son descartados, en esta misma línea, los derechos a la corresponsabilidad educativa, la perspectiva de género, la responsabilidad parental, a tener y no separarse de la familia y a la intimidad, ratificados por los artículos 10, 12, 14, 22 y 33 de la Ley 1098 de 2006.

Visto lo anterior de otra manera, se puede apreciar que de los 38 derechos fundamentales tomados como referencia en el Cuadro 1, en el Manual de Convivencia de la Institución Edu- cativa Técnico Industrial Blas Torres de la Torre (ITIDA) de Soledad, 25 (65.8\%), son excluidos, mientras los 13 restantes $(34.2 \%)$, son tenidos en cuenta. De estos 13 derechos fundamentales, 11 corresponden a los Derechos Humanos, y dos, a los Derechos Sexuales y Reproductivos, lo que representa el $36.7 \%$ y el $25 \%$, en forma respectiva, de los 30 Derechos Humanos y los ocho Derechos Sexuales y Reproductivos inventariados en el Cuadro 1.

En lo relativo al Manual de Convivencia de la Institución Educativa Distrital San José de Barranquilla, son reconocidos los derechos de los estudiantes que aparecen relacionados en el siguiente cuadro:

Cuadro 5. Derechos de los estudiantes. Institución Educativa Distrital San José de Barranquilla

Derechos Humanos contenidos en la Constitución Política de Colombia

1. Disfrutar de buenas relaciones y ser tratado con respeto y dignidad (art. 12)

2. Ser respetado en lo referente a la libertad de cultos (art. 19)

3. Libertad personal y de conciencia (art. 18)

Derechos Humanos contenidos en la Ley 1098 de 2006

4. Participar en la elaboración y realización del PEl a través de la convocatoria que hace el Consejo Directivo (art. 42).

Derechos Institucionales

5. Comunicar iniciativas, inquietudes y sugerencias que contribuyan al buen funcionamiento del colegio.

6. Conocer periódicamente los informes sobre su proceso de enseñanza-aprendizaje.

7. Tener la oportunidad de comunicar las situaciones problemáticas que interfieren en el proceso educativo.

8. A presentar evaluaciones en fechas posteriores cuando haya excusas justificadas.

9. Recibir información oportuna y participar de todas las actividades programadas en la institución

10. Ser reconocido y recibir estímulos por sus esfuerzos y logros en su proceso educativo

11. Disponer de los servicios de psicorientación.

Fuente: Manual de Convivencia de la Institución Educativa Distrital San José de Barranquilla (sección Derechos de los Estudiantes)

Ahora bien, si se comparan los derechos fundamentales contenidos en el Cuadro 5 con respecto a los contenidos en el Cuadro 1 de referencia, se puede colegir que de los 38 derechos fundamentales contenidos en este último, 34 de ellos $(89.5 \%)$, son omitidos en el manual de convivencia de la Institución Educativa Distrital San José de Barranquilla, y sólo cuatro (10.5\%) de estos derechos, son incluidos. De estos 4 derechos fundamentales incluidos, todos corresponden al ámbito de los Derechos Humanos, y ninguno, a los Derechos Sexuales y Reproducti- vos, lo que representa el $13.3 \%$ y el $0 \%$, respectivamente, de los 30 Derechos Humanos y los ocho Derechos Sexuales y Reproductivos relacionados en el Cuadro 1.

Visto lo anterior de otra manera, se puede precisar que los dos Derechos Humanos incluidos en este manual de convivencia, son los derechos al buen trato, a la libertad de conciencia, a la libertad de culto, y a participar en el proceso educativo. Los tres primeros, reconocidos en los artículos 12, 18 y 19 de la Constitución de 
1991, y el último, en el artículo 42 de la Ley 1098 de 2006. Adicionalmente, se incorporan los numerales 5 al 11 que sólo competen al marco de esta institución educativa.

El análisis comparativo, igualmente deja ver que el Manual de Convivencia de la Institución Educativa Distrital San José de Barranquilla, omite derechos humanos fundamentales como los contenidos en los artículos 11, 12, 13, 20, 21, 22, 23, 29, 37, 38, 40, 41, 45, 49, 52, 67 y 79 de la Constitución Política de Colombia. Todos ellos, referentes a los derechos a la vida, a la igualdad ante la ley, a la libertad de expresión, a la honra, a vivir en paz, de petición, al debido proceso, a la libertad de reunión, a la libertad de asociación, a elegir y ser elegido, a la educación ciudadana, a la formación integral, a un ambiente sano, a la recreación, a la educación y a la salud. Así mismo, se pasa por alto Derechos Humanos básicos como los contemplados en los artículos
$7,18,19,20,21,26,27,28,29,30$ y 36 de la Ley 1098 de 2006. Es decir, los derechos a la protección integral, a la integridad personal, a la rehabilitación y resocialización, a la protección, a la seguridad personal, al desarrollo integral, de los niños con discapacidades. Por otra parte, son excluidos los Derechos Sexuales y Reproductivos a la intimidad, al libre desarrollo de la personalidad, a la corresponsabilidad educativa, la perspectiva de género, la responsabilidad parental, a tener y vivir en familia y a la identidad. Derechos que son reconocidos en los artículos 15 y 16 de la Constitución de 1991, los dos primeros, y en los artículos, 10, 12, 14, 22 y 25 de la Ley 1098 de 2006.

En cuanto al Manual de Convivencia de la Institución Educativa Antonia Santos de Molinero (Atlántico), en su artículo $6^{\circ}, 7^{\circ}, 8^{\circ}$ y $9^{\circ}$, son reconocidos a los estudiantes los derechos que aparecen relacionados en el Cuadro 6:

Cuadro 6. Derechos de los estudiantes. Institución Educativa Antonia Santos de Molinero

\begin{tabular}{|c|}
\hline Derechos Humanos contenidos en la Constitución de 1991 \\
\hline 1. A recibir un trato amable de toda la comunidad educativa sin ninguna discriminación (art. 12) \\
\hline 2. Al mismo trato y derechos, libertades y oportunidades sin discriminación alguna 13 (art. 13 \\
\hline 3. A la libertad de expresar y difundir sus pensamientos, opiniones, informar y recibir información (art. 20) \\
\hline 4. A la honra (art. 21) \\
\hline 5. A disponer de un ambiente de paz, armonía y solidaridad (art. 22) \\
\hline 6. Hacer uso del Derecho de Petición (art. 23) \\
\hline 7. Al debido proceso y a la legítima defensa (art. 29) \\
\hline 8. A elegir y ser elegido (art. 40) \\
\hline 9. A disfrutar del descanso, recreación, práctica del deporte y aprovechamiento del tiempo libre (art. 52) \\
\hline 10. A la formación integral (art. 67) \\
\hline 11. A contar con un Seguro médico estudiantil contra accidentes que garantice su protección (art. 79) \\
\hline Derechos Humanos contenidos en la Ley 1098 de 2006 \\
\hline 12. A Participar en las jornadas pedagógicas, intercambios deportivos, artísticos, culturales y otros (art. 42) \\
\hline 13. A participar en la planeación, ejecución y evaluación del PEI (art. 42) \\
\hline 14. A participar activamente en la elaboración de planes y proyectos de áreas o asignaturas (art. 42) \\
\hline 15. A participar en el proceso educativo o actividades académicas (art. 42) \\
\hline Derechos Sexuales y Reproductivos contenidos en la Constitución de 1991 \\
\hline 16. Al desarrollo de su personalidad (art. 16) \\
\hline 17. A la intimidad personal, familiar y al buen nombre (art. 16) \\
\hline Derechos Sexuales y Reproductivos contenidos en la Ley 1098 de 2006 \\
\hline 18. Ser respetado(a) en la integridad personal, sexual y creencias religiosas (art. 43) \\
\hline Derechos Institucionales \\
\hline 19. Recibir el Manual de Convivencia al momento de la matrícula o de su renovación. \\
\hline
\end{tabular}


20. Ser escuchado cuando necesite dialogar con los directivos y los docentes en el momento oportuno.

21. A recibir las clases de acuerdo al horario académico reglamentado por el MEN y el PEl.

22. A utilizar en forma adecuada la planta física del colegio al igual que sus recursos

23. Solicitar permiso al rector para el desarrollo de actividades extramurales.

24. A conocer los principios que orientan la legislación educativa del país y de la institución

25. Utilizar y recibir oportunamente los servicios de Bienestar Estudiantil que presta el colegio

26. A participar en el Gobierno Escolar para trabajar en beneficio de la Institución.

27. A ser atendido(a) oportuna y debidamente por parte del personal administrativo

28. A recibir orientación formativa en todos los aspectos de su desarrollo integral durante su escolaridad.

29. A recibir los primeros auxilios con que cuenta la Institución.

30. A presentar propuestas de actividades que puedan realizarse en la Institución

31. A promover y participar en campañas que busquen el bienestar y superación estudiantil e Institucional.

32. A recibir oportunamente el Carnet estudiantil

33. A recibir reconocimientos públicos cuando se haga merecedor(a) a ellos

34. A recibir una bibliografía amplia que permita hacer las consultas

35. A recibir las orientaciones pertinentes del proceso pedagógico durante el desarrollo de las clases.

36. A ser evaluado de manera integral, sistemática y permanente

37. A conocer oportunamente los resultados de las evaluaciones y solicitar revisiones de los resultados.

38. Conocer sus logros y/o dificultades oportunamente por parte de sus profesores.

39. Recibir informe escrito al finalizar cada período y reclamar respetuosamente cuando lo crea conveniente.

40. Exigir puntualidad y preparación académica a los profesores.

41. Recibir los estímulos y distinciones a los cuales, de acuerdo a su desempeño, se haya hecho acreedor.

42. Presentar sus trabajos y evaluaciones en las fechas acordadas después de una o más ausencias justificadas.

43. Solicitar calidad y un buen servicio educativo.

44. Recibir directamente del profesor, las evaluaciones realizadas en su respectiva hora de clase.

45. En caso de seguimiento convivencial del estudiante, el padre de familia deberá conocer los acuerdos

46. Recibir información oportuna sobre las actividades programadas en el cronograma.

47. Ser escuchado antes de ser sancionado.

48. Hacer las sugerencias que considere necesarias para su formación y buena marcha de la Institución.

49. Conocer y hacer valer sus derechos.

Fuente: Manual de Convivencia, Institución Educativa Antonia Santos de Molinero, Arts. $6^{\circ}, 7^{\circ}$, $8^{\circ}$ y $9^{\circ}$.

Ahora bien, si se examina los derechos incluidos en el cuadro anterior y se le compara con los derechos fundamentales contenidos en el Cuadro 1 tomado como referente, se puede apreciar que de los 38 derechos fundamentales inventariados en este último, 20 de ellos $(52.6 \%)$ son omitidos al elaborar el manual de convivencia de la Institución Educativa Antonia Santos de Molinero. Los 18 restantes $(51.4 \%)$, son incluidos. De los 18 derechos fundamentales incluidos, 15 corresponden a los Derechos Humanos, y tres, a los Derechos Sexuales y Reproductivos, lo que representa el $50.0 \%$ y el $37.5 \%$, respectivamente, de los 30 Derechos Humanos y los
8 Derechos Sexuales y Reproductivos tomados como referente en el Cuadro 1.

Visto lo anterior en detalle, el cotejo entre los derechos relacionados en el Cuadro 6 y el Cuadro 1 tomado como referente, pone de presente que en la Institución en el manual de convivencia de la Institución Educativa Antonia Santos de Molinero, son reconocidos los derechos fundamentales contenidos en los artículos 12, 13, 20, 21, 22, 23, 29, 40, 52, 67 y 79 de la Constitución Política Nacional de Colombia. Se hace referencia a los derechos al buen trato, a la igualdad ante la ley, a la libertad de expresión, a la honra, 
a vivir en paz, de petición, al debido proceso, a elegir y ser elegido, al descanso y la recreación, a la formación integral y a la salud.

También, en la elaboración de este manual de convivencia son tomados en consideración los derechos fundamentales a participar en la planeación, ejecución y evaluación del Proyecto Educativo Institucional, de las actividades curriculares y extracurriculares, así como en el proceso educativo. Derechos que se encuentran circunscritos en los artículos 42 de la Ley 1098 de 2006. Asimismo, se tienen en cuenta los Derechos Sexuales y Reproductivos a la intimidad, al libre desarrollo de la personalidad y a la integridad personal y sexual, reconocidos en los artículos 15 y 16 de la Constitución de 1991, los dos primeros, y el último, por el artículo $1^{\circ}$ de la Ley 1620 de 2013.

Ahora bien, el cotejo entre los cuadros 1 y 6 , igualmente pone de presente, que en el manual de convivencia de la Institución Educativa Antonia Santos de Molinero, son omitidos los derechos a la vida, a la libertad de conciencia, a la libertad de cultos, a reunirse y manifestarse, a la libre asociación, a la educación ciudadana, a la formación integral y a un ambiente sano. Derechos reconocidos en los artículos 11, 18, 19, 37, 38, 41, 45 y 49 de la Constitución de 1991. También, son desconocidos Derechos Humanos fundamentales como los contenidos en los artículos 7, 18, 19, 20, 21, 29, 34 y 36 de la Ley 1098 de 2006. Se hace referencia a los derechos a la protección integral, a la integridad personal, a la rehabilitación y resocialización, a la protección, a la seguridad personal, al desarrollo integral y de los niños con discapacidades.

En lo que respecta al Manual de Convivencia de la Institución Educativa León XIII de San Jacinto (Bolívar), en su Artículo 22, se registran los derechos que aparecen en el Cuadro 7:

Cuadro 7. Derechos de los Estudiantes. Institución Educativa León XIII de San Jacinto

\begin{tabular}{|c|}
\hline Derechos Humanos reconocidos en la Constitución de 1991 \\
\hline 1. Ser tratados con la consideración, respeto, aprecio y justicia (art. 12) \\
\hline 2. Ser escuchado antes de iniciar el proceso disuasivo (art. 29) \\
\hline 3. Recibir formación integral (art. 45) \\
\hline 4. Facilitar el acceso y permanencia al sistema educativo (art. 67) \\
\hline Derechos Humanos reconocidos por la Ley 1098 de 2006 \\
\hline 5. Ser protegido contra toda forma de abandono, violencia, descuido, abuso (art 7) \\
\hline 6. No ser amenazado, ridiculizado o intimidado en público o privado (art. 43) \\
\hline 7. Ser aceptado sin ninguna limitación (art. 43) \\
\hline 8. Participar activamente en el proceso del aprendizaje y demás programaciones (art. 42) \\
\hline Derechos Sexuales y Reproductivos reconocidos por la Ley 1098 de 2006 \\
\hline 9. Ser aceptada en condición de embarazo, sin que afecte proceso educativo (art. 22) \\
\hline Derechos Institucionales \\
\hline 10. Conocer con anterioridad las programaciones \\
\hline 11. Recibir información clara y oportuna sobre las normas que este Manual contempla \\
\hline 12. Conocer anticipadamente sus evaluaciones finales antes de socializarlos \\
\hline 13. Ser atendido en sus reclamos y solicitudes particulares \\
\hline 14. Conocer las anotaciones sobre su comportamiento de convivencia \\
\hline 15. Utilizar y recibir oportunamente los servicios de bienestar disponible en la Institución \\
\hline 16. Ser atendido oportuna y debidamente por parte del personal administrativo \\
\hline 17. Solicitar los medios que les permita expresar sus opiniones, quejas y denuncias \\
\hline 18. Promover y participar en campañas que busquen el bienestar y superación personal \\
\hline
\end{tabular}

Fuente: Manual de Convivencia. Institución Educativa León XIII de San Jacinto, (Art. 22). 
El cotejo de los cuadros 1 y 7 pone de presente, que de los 38 derechos fundamentales relacionados en el Cuadro 1, son omitidos en el manual de convivencia de la Institución Educativa León XIII de San Jacinto, 29 de ellos (76.3\%), en tanto, los 9 restantes $(23.7 \%)$, son ratificados. De estos 9 derechos reconocidos, 8 corresponden a Derechos Humanos, y uno, a los Derechos Sexuales y Reproductivos, que representan el $26.7 \%$ y el $12.5 \%$, respectivamente, de los 30 Derechos Humanos y los ocho Derechos Sexuales y Reproductivos relacionados en el Cuadro 1. Visto lo anterior desde otra perspectiva, el análisis comparativo entre los cuadros 1 y 7 , también permite evidenciar que en este manual de convivencia son incluidos los Derechos Humanos relativos al buen trato, al debido proceso, a la formación integral y a la educación, reconocidos en los artículos 12, 29, 45 y 67 de la Constitución de 1991. También, son tenidos en cuenta los derechos de los niños y jóvenes a la protección integral, a la protección, a ser aceptado y a participar en los procesos educativos, ratificados en los artículos 7, 20, 42 y 43 de la Ley 1098 de 2006. Igualmente, se incorpora el Derecho Sexual y Reproductivo de las jóvenes a ser aceptada en condiciones de embarazo, reconocido en el artículo 22 de la misma ley.

No obstante, el cotejo entre los cuadro 1 y 7 , también pone de relieve que en el manual de convivencia de la Institución Educativa León XIII de San Jacinto (Bolívar), no se toman en consideración los derechos humanos contenidos en los artículos 11, 13, 18, 19, 20, 21, 22, 23, 37, 38, 40, 41, 49, 52 y 79 de la Carta Magna. Artículos, que en orden respectivo, ratifican los Derechos Humanos a la vida, a la igualdad ante la ley, a la libertad de conciencia, a la libertad de cultos, a la libertad de expresión, a la honra, a vivir en paz, a realizar peticiones respetuosas, a la libertad de reunión, a la libre asociación, a elegir y ser elegido, a la educación ciudadana, a un ambiente sano, al descanso y la recreación y a la salud.

Asimismo, se pasan por alto los Derechos $\mathrm{Hu}-$ manos fundamentales reconocidos en los artículos 18, 19, 20, 21, 29 y 36 de la Ley 1098 de 2006, referentes a la integridad personal, a la rehabilitación y resocialización, a la protección, a la seguridad personal, al desarrollo integral, de los niños con discapacidades. También, son omitidos los Derechos Sexuales y Reproductivos referentes a la intimidad, el libre desarrollo de la personalidad, a la corresponsabilidad educativa, a la perspectiva de género, a la responsabilidad parental, a la identidad y a la intimidad. Reconocidos, los dos primeros, en los artículos 15 y 16 de la Constitución de 1991, y cinco últimos, en los artículos 10, 12, 14, 25 y 33 de la Ley 1098 de 2006.

Ahora bien, el análisis comparativo y de conjunto entre los derechos contenidos en los diferentes manuales de convivencia estudiados y los derechos fundamentales tomados como referente, nos pone de presente que los distintos reglamentos institucionales reconocen muchos de los derechos fundamentales contenidos en la Constitución de 1991 y la Ley 1098 de 2006. Sin embargo, también pone de relieve que un buen número de estos derechos, son omitidos en los corpus reguladores de la convivencia escolar y garantes del ejercicio y respeto de los Derechos Humanos, Sexuales y Reproductivos en las instituciones educativas.

Más exactamente, el cotejo de los derechos fundamentales contenidos en el Cuadro 1 tomado como referente, con respecto a los derechos incluidos en los diferentes manuales de convivencia examinados, arroja los resultados que aparecen en la siguiente gráfica: 
Grafica 1. Cotejo entre de los derechos fundamentales tomados como referente y los derechos fundamentales incluidos en los manuales de convivencia examinados.

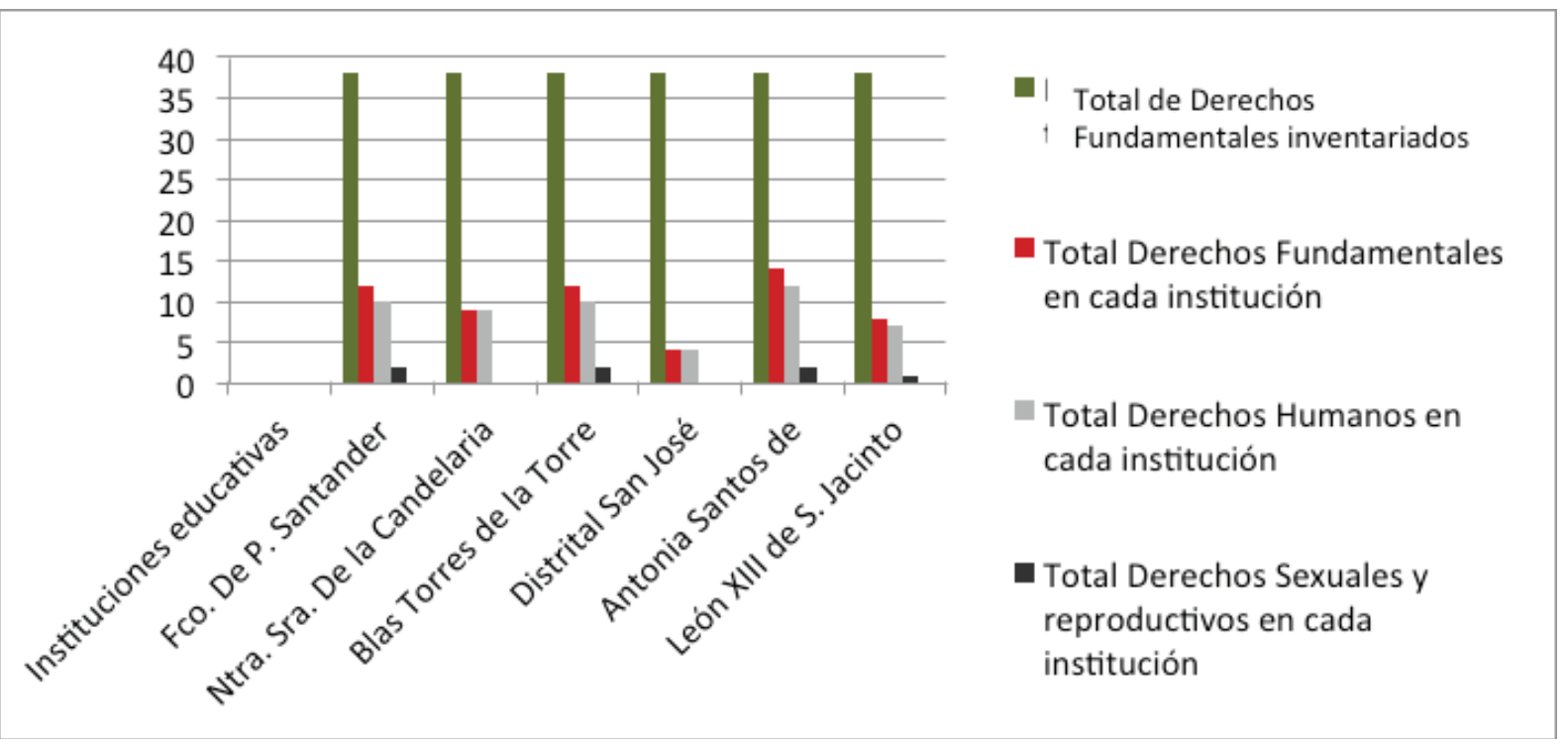

Fuente: Constitución de 1991, Ley 1098 de 2006, manuales de convivencia de las instituciones educativas Francisco de Paula Santander de Galapa, Nuestra Señora de la Candelaria de Malambo, Blas Torres de la Torre de Soledad, Distrital San José de Barranquilla, Antonia Santos de Molinero y León XIII de San Jacinto.

Ahora bien, si inicia el análisis del cuadro anterior por los totales arrojadas al final del mismo, se puede observar, por una parte, que de los 38 Derechos Humanos, Sexuales y Reproductivos tomados como referente, sólo son incluidos en promedio en los distintos manuales de convivencia estudiados, el $25.9 \%$ de estos derechos fundamentales, en tanto, el $74.1 \%$, son omitidos. Asimismo, se puede apreciar, que de los 30 derechos clasificados como Derechos Humanos, son tomados en consideración en los distintos reglamentos escolares analizados, el $28.9 \%$ en promedio, mientras el $71.9 \%$ restantes, se pasan por alto.

\section{Conclusión a manera de síntesis:}

A continuación Derechos humanos que se omiten y los que más se incluyen en los manuales de convivencia de estudio, datos que en la investigación aparecen como anexos de la misma

Grafico 2. Derechos humanos que se omiten en los manuales de convivencia de estudio.

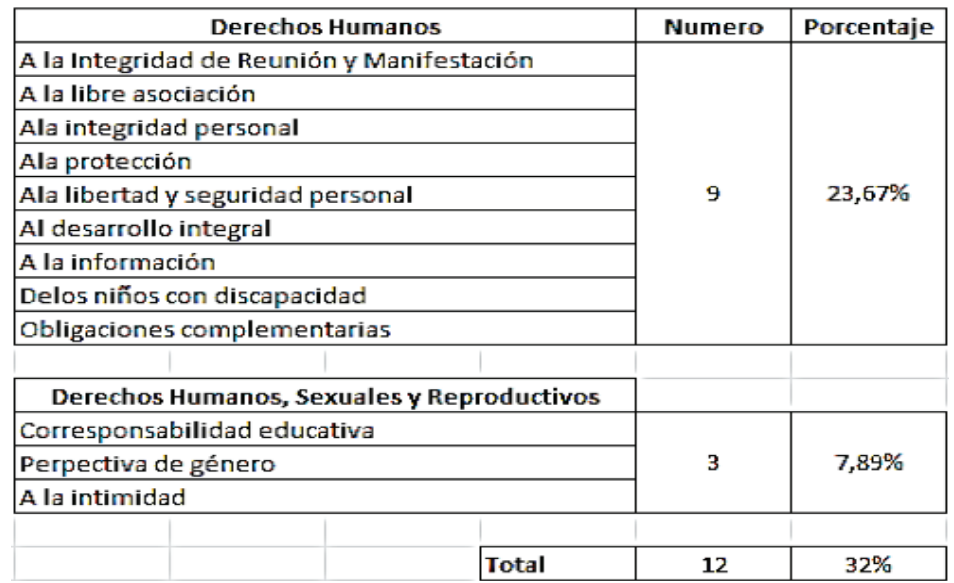


Grafico 3. Los Derechos Humanos que mas se incluyen en los manuales de convivencia de estudio

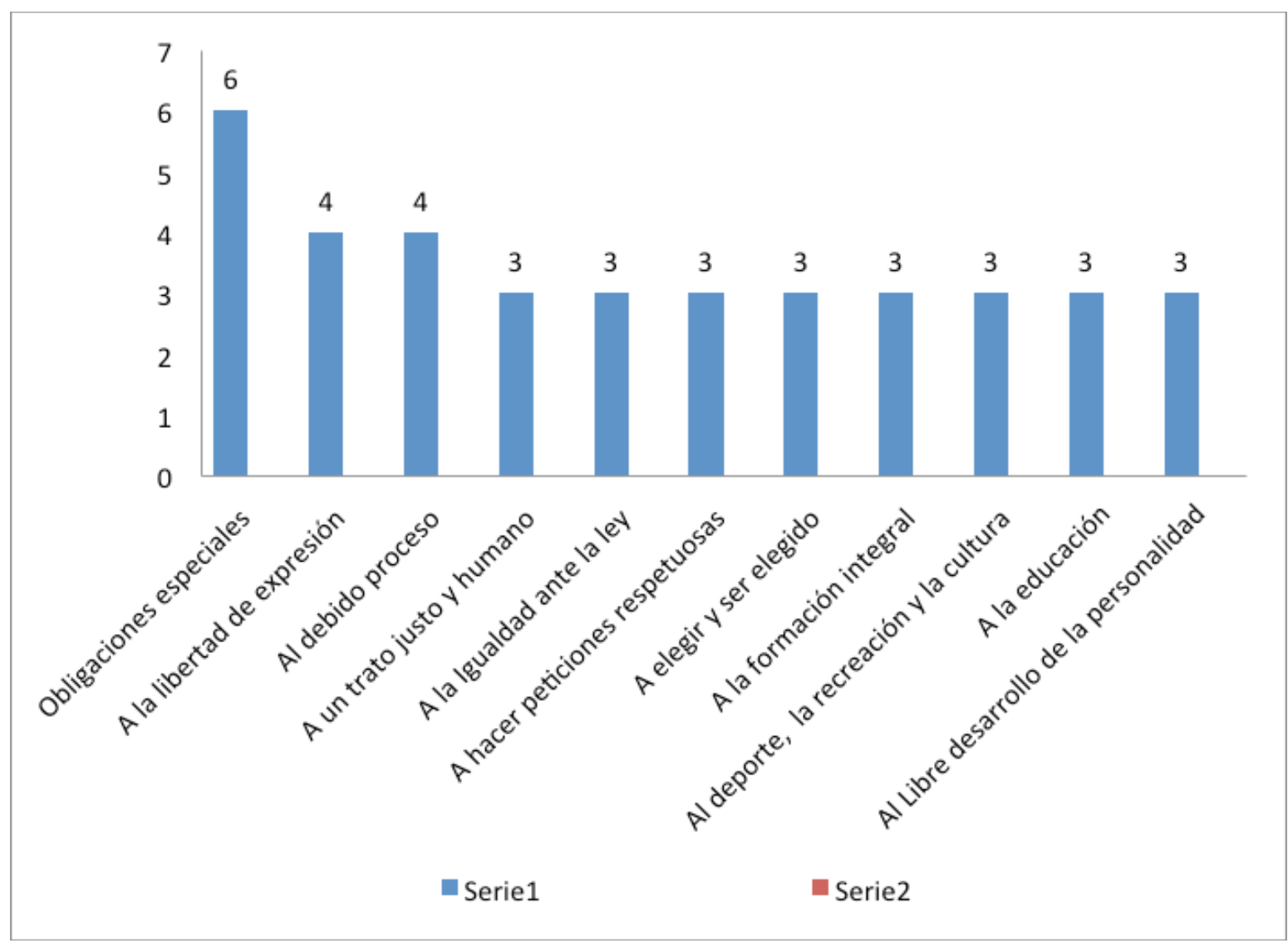

Fuente: Constitución de 1991, Ley 1098 de 2006, manuales de convivencia de las instituciones educativas Francisco de Paula Santander de Galapa, Nuestra Señora de la Candelaria de Malambo, Blas Torres de la Torre de Soledad, Distrital San José de Barranquilla, Antonia Santos de Molinero y León XIII de San Jacinto.

\section{Referencias bibliográficas.}

Areira Bedoya, E., Cano Zapata, A. E. y Jaramillo Roldán, R. (2004). Los Manuales de Convivencia Escolar en la Educación Oficial de Antioquia. Recuperado de: http:/ / tesis.udea. edu.co / dspace / bitstream / 10495 / 3081 / 1 / JaramilloRodrigo_2004_manualesconvivenciaescolareducacionoficial.pdf, el día 2 de abril de 2014.

Arrieta Barbosa, A. (2016). Los manuales de convivencia escolar: ¿documentos formativos o coercitivos? Manuscrito en preparación. Barranquilla: Universidad del Atlántico.

Asamblea Nacional Constituyente. (1991). Constitución Politica de Colombia. Recuperada de http: / / web.presidencia.gov.co/ constitucion / index.pdf, el día 23 de febrero de 2016.

-Bermejo, E. M., Sarmiento Domínguez, C. y Vizcaíno Lazcano, D. (2015). Estrategia educativa para la mitigación-prevención de la violencia escolar de los estudiantes de Educación Media. Barranqui1la: Universidad Autónoma del Caribe.

-Bernal Martínez, M. Y Saker García, J. (2013). La convivencia: mirada en las instituciones educativas del distrito de Barranquilla. Barranquilla: Universidad de la Costa.

-Boada, M. M., Agudelo, A., González, F., Hernández, G., Moreno, D. M., Quintero, I., Rojas, E., Ramírez, C. y Mosquera, W. (2001). La Convivencia Escolar. Una vida, un aprendizaje. Bogotá: Centro Educativo Distrital Rómulo Gallegos. 
Recuperado el día 22 de febrero de 2016 de: http: / / www.pedagogica.edu.co/storage/ rce / articulos / pag099-105.pdf

-Caballero Grande, M. J. (2010). Convivencia escolar. Un estudio sobre buenas prácticas. Revista Paz y Conflictos, Núm. 3, pp. 154-169. Recuperado de: www.ugr.es/ revpaz/tesinas/ rpc_n3_2010_dea5.pdf, el día 19 de febrero de 2016.

-Caballero Prieto Piedad, Bonilla Esperanza, Torres Patricia y Fonseca Andrés. (2009). Evaluación Manuales de convivencia escolar: aplicación de contenidos y Participación activa de niños, niñas y adolescentes en su definición -Magdalena, Boyacá y Soacha-. Bogotá: Universidad Pedagógica Nacional.

-Cangas, A. J., Gázquez, J. J., Pérez Fuentes, C., Moldes, P. y Rubio, C. (2007). Influencia de las características familiares en la percepción de los conflictos de convivencia escolar. Típica: Boletín electrónico de salud escolar, Vol. 3, Núm. 1. Recuperado el día 20 de febrero de 2013 de: Http: / / www.tipica.org/pdf/cangas_caracteristicas_ familiares_y_conflictos_de_convivencia_escolar.pdf.

-Casas, L. (2008). La convivencia escolar, componentes indispensables del derecho a la educación (Estudio de Reglamentos Escolares). Serie Reflexiones: Infancia y adolescencia No 11. Santiago de Chile: Unicef.

-Cogollo Padilla, I. M y Peña Mendivil, F. A. (2014). (Tesis de Maestría). Estructura y funcionamiento familiar de los estudiantes de educación básica de 12-14 años que presentan conducta agresiva, pertenecientes a las instituciones educativas Francisco de Paula Santander de Galapa y Betsabé Espinosa del Distrito de Barranquilla. Barranquilla: Universidad Simón Bolívar.

Comisión Nacional de Derechos Humanos México (2016). ¿Qué son los derechos humanos? Recuperado el día 17 de junio de 2016 de: http:/ / www.cndh.org.mx/Que_son_Derechos_Humanos, el día 08 de julio de 2016.
-Congreso de la República de Colombia (2013). Decreto 1965 de 2013. Recuperado de: http: / / www.mineducacion.gov.co/1759/articles-327397_archivo_pdf_proyecto- decreto. pdf, el día 14 de mayo de 2016.

(2013). Ley 1620 de 13 de marzo de 2013. Documento recuperado de: http://wsp.presidencia.gov.co / Normativa / Leyes / Documents / 2013 / LEY\%201620\%20DEL \%2015\%20 DE\%20MARZO\%20DE\%202013.pdf, el día 23 de febrero de 2016.

(2006). Ley 1098 de 8 de noviembre de 2006. Recuperado el día 25 de mayo de 2016 de: www. oei.es / quipu/Colombia / codigo_infancia.pdf (1997). Ley 375 de 4 de julio de 1997 o Ley de la Juventud. Recuperado de: http: / / www.mineducacion.gov.co/1621/articles-85935_archivo_pdf.pdf, el día 17de mayo de 2013.

-Conde Vélez, S. (2013). Estudio de la gestión de la convivencia escolar en centros de Educación Secundaria de Andalucía: una propuesta de evaluación basada en el Modelo EFQM. Huelva: Universidad de Huelva. Recuperado de: http: / / rabida.uhu. es / dspace / bitstream / handle / 10272 / 6438 / Estudio_de_la_gestion_de_la_convivencia.pdf? sequence=2, el día 12 de febrero de 2016.

Corte constitucional (2013). Sentencia T-565 de 2013. Recuperada de: http:/ / corteconstitucional.gov.co/relatoria/2013/t-565-13.htm, el día 20 de julio de 2016.

(2011). Sentencia T-390 de 2011. Recuperada el día 21 de julio de 2016 de: http:/ / www.corteconstitucional.gov.co/ relatoria/2011/t-390-11.htm

(2003). Sentencia T-1233 de 2003. Recuperada el día 23 de julio de 2016 de: http: / / www.corteconstitucional.gov.co/ relatoria/2003/t-1233-03.htm

(1999). Sentencia T-695 de 1999. Recuperada el día 22de julio de 2016 de: http:/ / www.corteconstitucional.gov.co/ relatoria/1999/T-695-99.htm

(1998). Sentencia SU-641 de 1998. Recuperada el día 21 de julio de 2016 de: http: / / www.corteconstitucional.gov.co/ relatoria/1998/ su641-98.htm

(1997). Sentencia T-366 de 1997. Recuperada el día 20 de julio de 2016 de: http:/ / 
www.corteconstitucional.gov.co/ relatoria/1997/T-366-97.htm

(1997). Sentencia T-375 de 1997. Recuperada el día 19 de julio de 2016 de: http: / / www.corteconstitucional.gov.co/ relatoria/1997/T-375-97.htm

(1995). Sentencia T-037 de 1995. Recuperada el día 23 de julio de 2006 de: http:/ / www.corteconstitucional.gov.co/ relatoria/1995/t-037-95.htm

(1994). Sentencia T-015 de 1994. Recuperada el día 21 de julio de 2016 de: http: / / www.corteconstitucional.gov.co/ relatoria/1994/T-015-94.htm

(1994). Sentencia T-386 de 1994. Recuperada el día 19 de julio de 2016 de: http: / / www.corteconstitucional.gov.co/ relatoria/1994/t-386-94.htm

(1992). Sentencia T-532 de 1992. Recuperada el día 19 de julio de 2016 de: http: / / www.corteconstitucional.gov.co/ relatoria/1992/T-532-92.htm

(1992). Sentencia T-366 de 1992. Recuperada el día 19 de julio de 2016 de: http: / / www.corteconstitucional.gov.co/ relatoria/1997/ T-366-97.htm

(1992). Sentencia T-524 de 1992. Recuperada el día 19 de julio de 2016 de: http: / / www.corteconstitucional.gov.co/ relatoria/1992/t-524-92.htm

Delors J. (1996). Informe de la Unesco de la Comisión Internacional sobre la educación para el siglo XXI: La Educación encierra un tesoro. Madrid: Santillana- Ediciones Unesco.

-Guardián-Fernández, A. (2007). El Paradigma Cualitativo en la Investigación Socio-Educativa. San José de Costa Rica: Coordinación Educativa y Cultural Centroamericana (CECC), Agencia Española de Cooperación Internacional (AECI). Recuperado el día 2 de abril de 2016 de: http: / / web.ua.es/ en / ice/ documentos / recursos / materiales / el-paradigma-cualitativo-en-la-investigacion-socio-educativa.pdf

-Garretón Valdivia, P. (tesis doctoral). (2013). Estado de la convivencia escolar, conflictividad y su forma de abordarla en establecimientos educacionales de alta vulnerabilidad social de la provincia de con- cepción, chile. Córdoba: Universidad de Córdoba. Recuperado el día 18 de febrero de 2016 de: http: / / helvia.uco.es / xmlui / bitstream/ handle $/ 10396 / 11611 / 2014000000906$.pdf? sequence=1.

-Gil Bautista, L. L. (2014). Diagnóstico de la situación de convivencia escolar de la institución educativa Omar Antonio Muñoz Gutiérrez. Ibagué: Universidad del Tolima. Recuperado el día 20 de febrero de 2016 de: http: / / repository. ut.edu.co/ bitstream / 001 / 1181 / 1 / RIUT-BHAspa-2014-Diagn\% C3\%B3stico\%20de\%20la\%20 situaci $\%$ C3\% B3n $\% 20 \mathrm{de} \% 20$ convivencia $\% 20$ escolar\%20de $\% 201 \mathrm{a} \% 20 \mathrm{instituci} \% \mathrm{C3} \% \mathrm{~B} 3 \mathrm{n} \% 20$ educativa.pdf

-Guzmán Muñoz, E. J., Muñoz, J. y Preciado Espitia, A. (2012). La Convivencia Escolar: Una mirada desde la diversidad cultural. Manizales: Universidad de Manizales. Recuperado el día 23 de febrero de 2016 de: http:// ridum.umanizales.edu.co:8080/jspui / bitstream/6789/1066/1/109_Preciado_Espitia_ Edgar_Alexander_Tesis.pdf

-Hernández Sampieri, R., Fernández, Collado, C. y Batipta, Lucio, P. (1991). Metodología de la Investigación. México: McGraw-Hill, Sexta Edición (2014).

--Institución Educativa Antonia Santos. Manual de Convivencia. Corregimiento de Molinero, Departamento del Atlántico, Colombia.

-Institución Educativa Distrital San José (2011). Manual de Convivencia. Barranquilla, Departamento del atlántico, Colombia.

-Institución Educativa León XIII. (2015). Manual de Convivencia. San Jacinto, Departamento de Bolívar, Colombia.

-Institución Educativa Nuestra Señora de la Candelaria (2016). Manual de Convivencia. Malambo, Departamento del atlántico, Colombia. -Institución Educativa Técnico Industrial Blas Torres de la Torre ITIDA. (2015). Manual de Convivencia. Soledad, Departamento del Atlántico, Colombia. 
-Institución Educativa Técnica Francisco de Paula Santander de Galapa. (2014). Manual de Convivencia. Galapa, Departamento del Atlántico, Colombia.

-Instituto Colombiano para el Fomento de la Educación Superior (ICFES). (2013). Sistema Nacional de Evaluación Estandarizada de la Educación - Alineación del examen SABER $11^{\circ}$. Documento recuperado el día 24 de abril de 2016 de: http: / / www.icfes.gov.co / examenes / component / docman/doc_view/775-alineacion-del-examen-saber-11?Itemid=

-Krippendorff, K. (1990). Metodología de análisis de contenido. Barcelona-Buenos Aires-México: Ediciones Paidós.

Ministerio de Educación Nacional. (2014). Guías para el apoyo a la implementación de la Ley de Convivencia Escolar. Recuperado el día 13 de mayo de 2016 de:http:/ / www.mineducacion.gov. co/1759/articles-326662_archivo_pdf_Dia1_ No_1_Reglamentacion_LEY_1620_Encuentros_Regionales.pdf

(2013). Guía 49 de 2013. Recuperado el día 16 de mayo de 2016 de: http: / / www.mineducacion.gov.co/1621/article-339480.html, (2007). Plan Nacional de Educación 20062016. Documento recuperado el día 24 de marzo 2016 de: http://www.mineducacion.gov. co/1621/articles-312490_archivo_pdf_plan_ decenal.pdf

(2004). Estándares Básicos de Competencias en Ciencias Naturales y Ciencias Sociales. Serie Guías No 7. Recuperada el día 23-02-2013 de http: / / www.eduteka.org/pdfdir / MENEstandaresCienciasSociales2004.pdf.

(2002). Lineamientos Curriculares para el Área de Ciencias Sociales. Documento recuperado de: http: / / www.mineducacion.gov.co/1621/ articles-89869_archivo_pdf, el día 22 de 2016.

(1989- 1990). Marco General Propuesta

Programa Curricular Ciencias Sociales, Educación Básica, 60 , $7^{\circ}$, $8^{\circ}$ y $9^{\circ}$. Bogotá: Editorial Andes. Programa que desarrolla el Decreto No 1002 de 1984. Recuperado el día 24-02-2013 de http: / / www.mineducacion.gov.co/1621/articles-103663_archivo_pdf.pdf.
(1994). Ley 115 o Ley general de Educación de 8 de febrero de 1994. Documento recuperado el día 14 de abril de 2013 de: http: / / www. mineducacion.gov.co/1759/articles-124745_archivo_pdf9.pdf

(1994). Decreto 1860 de 3 de agosto de 1994. Documento recuperado el día 25 de mayo de 2013 de: http://www.mineducacion.gov. co/1621/articles-86240_archivo.pdf.

-Ministerio de Educación República de Chile. (2015). Política Nacional de Convivencia Escolar 2015-2018. Santiago de Chile. Recuperado el día 28-08-2016 de: http:/ / www.mineduc.cl/ wp-content/uploads/sites/19/2015/12/ politica-noviembre-definitiva.pdf

-Ocampo, M., Briceño, S., Hernández, M y Olano, M. (2010). Estrategias para mejorar la convivencia en el Colegio Cristóbal Colón, Instituto Educativo Distrital. En: Cuadernos Hispanoamericanos de Psicología, Vol. 10, Núm. 2, pp. 46-61. Bogotá: Universidad El Bosque. Recuperado el día 22 de febrero de 2013 de: Http: / / www. uelbosque.edu.co/sites / default/files / publicaciones / revistas / cuadernos_hispanoamericanos_psicologia/volumen10_numero2/articulo_4.pdf

-Organización de Naciones Unidas (1989). Convención Internacional de los Derechos del Niño. Documento recuperado el día 27 de julio de 2016 de: http:/ / www.un.org/es/events/ childrenday / pdf/ derechos.pdf

(1959). Declaración de los Derechos del Niño. Recuperado el día 23 de julio de 2016 de: http: / / www.humanium.org/es/ declaracion-1959/

(1948). Declaración Universal de los Derechos Humanos. Recuperado de:

http: / / www.hchr.org.co/ documentoseinformes / documentos / carceles /1_Universales / B\%E1sicos/1_Generales_DH/1_Declaracion_ Universal_DH.pdf

-Ortega, R. (2007). La convivencia: un regalo de la cultura a la Escuela. En Revista IDEA-La Mancha, No 4, pp. 50-54. Recuperada el día 24 de agosto de 2016 de: www.doredin.mec.es / documentos/00620073000911.pdf. 
-Patiño, Ochoa, D. S. (2011). La convivencia escolar como elemento fundante para una formación en ciudadanía. Montería: Universidad de Córdoba. Recuperado el día 24 de febrero de 2016 de: file: / / C: / Users / U / Downloads / Patino\%20 Ochoa\%20Diana\%20(2).pdf

-Pava Beltrán, D. C. (2015). Descripción de los elementos de la normatividad nacional que protegen los derechos humanos sexuales y reproductivos de la población LGBTI y su inclusión en los manuales de convivencia de los colegios, a la luz del Estudio de Caso del suicidio de Sergio Urrego. Buenos Aires: Facultad Latinoamericana de Ciencias Sociales - FLACSO Argentina. Recuperado el día 25 de octubre de 2016 de: http:// repositorio.flacsoandes.edu. ec/handle/10469/9564\#.WBivuy3hDIU

-Peralta Sánchez, F. J. (2004). Estudio de los problemas de convivencia escolar en estudiantes de enseñanza secundaria (Tesis doctoral). Málaga: Universidad de Málaga. Recuperado de: http: / / www.biblioteca.uma.es / bbldoc/ tesisuma/16789222.pdf, el día 12 de marzo de 2016.

-Quintero Romero, N. G. y Rentería Ramírez, L. F. (2009). Diseño de una estrategia de gestión educativa para mejorar los niveles de convivencia en el Colegio Rafael Uribe Uribe de Ciudad Bolivar, en la jornada de la mañana. Bogotá, D. C.: Pontificia Universidad Javeriana. Recuperado el día 19 de febrero de 2016 de: http: / / www.javeriana.edu. $\mathrm{co} / \mathrm{biblos} /$ tesis/educacion/tesis30.pdf

-Rodríguez García, P. L. y otros. (2011). Análisis de la convivencia escolar en aulas de educación primaria. Murcia: Universidad de Murcia, España. Recuperado el día 21 de febrero de 2016 de: Http: / / www.rieoei.org/expe/3839Garcia.pdf -Rodríguez Arévalo, V. (2011). El manual de convivencia escolar y el libre desarrollo de la personalidad. Una visión jurisprudencial. Revista Justicia Juris, Vol. 7. No 2. Julio - Diciembre 2011, pp. 17-26.

-Sanabria Mappe, L. E. (2013). Manual de convivencia y garantía de derechos: análisis del manual de convivencia de la Institución Educativa Guillermo Angulo Gómez de la ciudad de Ibagué Tolima. Ibagué: Universidad del Tolima. -San Juan López, M. A. (2008). Significados que otorgan a la convivencia escolar en aula estudiantes y profesores de educación media de una institución educativa. Santiago de Chile: Universidad de chile. Recuperado el día 24 de febrero de 2016 de: http: / / www.javeriana.edu.co/biblos / tesis/educacion/tesis30.pdf

-Strauss, A. y Juliet Corbin, J. (1998). Bases de la investigación cualitativa. Técnicas y procedimientos para desarrollar la teoría fundamentada. Medellín: Universidad de Antioquia. 